\title{
CARACTERES DE MUJERES PARALELAS Y FEMINIDAD EN LA OBRA DE DURRELL Y DE KAZANTZAKIS
}

\section{Helena González-Vaquerizo}

Universidad Autónoma de Madrid. España.

Resumen: Este artículo aborda la ficción de Nikos Kazantzakis y Lawrence Durrell con respecto a su narración de las mujeres protagonistas. La autora plantea que un enfoque comparativo en lo que respecta a las biografías de los dos escritores y sus novelas puede cambiar nuestros estereotipos relativos a la identidad de género y el papel de la mujer tanto en el trabajo de los autores como en su vida, revelando paralelismos inesperados entre sus personajes femeninos.

Palabras clave: Caracteres, mujeres paralelas, feminidad, Durrell, Kazantzakis.

\section{Parallel Women Characters and Femininity in Durrell's AND KaZANTZAKIS's WorK}

\begin{abstract}
This paper deals with Nikos Kazantzakis's and Lawrence Durrell's fiction with regard their narration of women protagonists. The author posits that a comparative approach to these writters both with regard to their biographies and their novels can change our stereotypes concerning gender identity and the role of women in both author's work and life showing unexpected parallels between their women characters.
\end{abstract}

Key words: Characters, parallel women, femininity, Durrell, Kazantzakis.

\section{Recibido: 12.11.2017 - Aceptado:13.01.2018}

\section{Correspondencia: Helena González Vaquerizo}

Email: helena.gonzalez@uam.es

Dept. Filología Clásica, Módulo III, Despacho 3.02., Facultad de Filosofía y

Letras. Universidad Autónoma de Madrid. España. 
Lawrence Durrell (1912-1990) y Nikos Kazantzakis (1883-1957) fueron contemporáneos y lo más importante, vivieron vidas un tanto paralelas. El primero fue un escritor británico expatriado y el último un autor cretense que vivió la mayor parte de su vida fuera de Grecia. Ambos se consideran a sí mismos ante todo poetas, aunque ambos se convirtieron en importantes novelistas. El Cuarteto de Alejandría de Durrell y de Kazantzakis Zorba el Griego son dos ejemplos conocidos. Por "paralelo" en el trabajo y la vida de Durrell y de Kazantzakis me refiero a una coexistencia, a que tienen la misma distancia entre ellos y a eventos que se producen o existen, al mismo tiempo o de forma similar. Por lo tanto, el paralelo no significa lo mismo ni es igual, pero sí quiere decir similar en diferentes niveles.

Sobre la base de las nociones anteriores, en el estudio que nos ocupa examino paralelos en la cosmovisión de Durrell y Kazantzakis, su concepción del mundo, su búsqueda de la síntesis y sus implicaciones en la comprensión de las relaciones hombre-mujer en el contexto de la historia mediterránea y oriental con su paganismo y espiritualidad. Durrell creía que una mujer libre conducirá al hombre a una nueva era, ya que los individuos libres son los únicos capaces de síntesis. Esto es elaborado por James Nichols en El sexo fuerte, un estudio sobre las mujeres en las novelas de Durrell. Kazantzakis, quien pasó la mayor parte de su vida luchando para llegar a la síntesis de las fuerzas opuestas, también creía en una visión del mundo similar. Durrell considera que la mujer es el centro de la experiencia: ella es la maestra del hombre y no su alumna. Ella es superior a él y la esperanza de la civilización. Para Kazantzakis la mujer era algo diferente del hombre; eso no quiere decir que ella sea inferior o superior, pero tampoco era su igual. Ambos escritores comparten el Mediterráneo y el Oriente (sobre Durrell y el orientalismo, véase, por ejemplo, Gifford $<$ http://dx.doi.org/10.7771/1481-4374.1036>). Como Nichols afirma en su libro, Durrell "llegó a afirmar y defender el materialismo del mundo clásico mediterráneo... En todas sus novelas, Durrell ve el cuerpo como igual, si no superior, al espíritu" (13) ${ }^{1}$. En el análisis de Nichols casi podemos oír

$1 \quad$ N. del T: Se han traducido las citas de obras originales en inglés, como esta de Nichols, pero también los textos de Kazantzakis, como los de Carta al Greco. Sin embargo, para el caso de la Odisea, hemos utilizado principalmente la traducción de Castillo Didier, que incorporamos en la bibliografía final del escrito respetando el espíritu de la autora. 
a Zorba de Kazantzakis decirle a su jefe que él comete un error buscando la vida en los libros y no en el mundo real. Para Zorba, como para Durrell, el conocimiento reside dentro del cuerpo y debe ser descubierto allí. Kazantzakis lo sabía, lo sentía, pero él también lo temía. Las verdades de la carne, la sexualidad y las mujeres lo asustaron y se refugió en el budismo y la espiritualidad.

El budismo fue para Kazantzakis lo que la India era para Durrell. Durrell fue criado en la India y vivió en muchos países diferentes y ambos escritores pasaron largos períodos en islas: Kazantzakis en Creta, Naxos, y Egina y Durrell en Corfú, Chipre y Rodas. Por un lado, compartieron el entorno natural en el que crecieron mezclados con el cosmopolitismo que adquirieron durante el curso de sus vidas. Por otro lado, sus antecedentes les proporcionan una comprensión particular del mundo: la dualidad oriental, una dualidad que, sin embargo, sí encaja en su compartido mundo pagano Mediterráneo. Nichols postula que "La unidad de toda la creación es clave tanto para el mundo clásico como para el supuesto misticismo del mundo oriental "(26) y esta unidad también es clave para los pensamientos paralelos de Kazantzakis y de Durrell que encontramos en sus textos. Durrell habló de una mentalidad tibetana y Kazantzakis de una mente occidental y un corazón de África y estos paralelismos se muestran en su concepción del arte y la vida. Para ellos, el arte y la vida son realidades iguales, imitaciones especulares entre sí: "falso sueño es la vejez y la muerte es fantasía; / todas las cosas del alma son creaciones y juegos del espíritu; / todo es brisa ligera que sopla y hace abrirse las sienes: / levemente el sueño fue soñado y llegó a ser este mundo" (Kazantzakis, Odisea, trad. Castillo Didier, 65-68). Kazantzakis creía en el poder de la imaginación para crear el mundo y reconoció el rol fértil de la mujer, mientras que Durrell fue más allá al postular que la mujer es la esencia creativa.

A fin de resumir su cosmovisión paralela me referiré a tres ideas de Nichols. Según él, el paganismo de Durrell afirma que: “1) la tragedia de la experiencia humana no es ni buena ni mala, sino simplemente inevitable; 2) la separación de la carne y del espíritu es falsa y destructiva para la felicidad humana, y 3) la libertad pura, ya sea física o psicológica, es una ilusión que, una vez reconocida, paradójicamente asegura su propia realidad»(30). Que la tragedia de la experiencia humana no es ni buena ni mala, sino simplemente inevitable para Kazantzakis es claro: cuando se le preguntó si estaba a favor o en contra de la guerra, él contestó que no estaba ni a favor ni en contra, como no estaba ni a favor ni en contra de un 


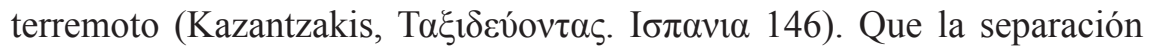
de la carne y el espíritu era para Kazantzakis falsa y destructiva para la felicidad humana es también relevante: Kazantzakis estaba preocupado por la forma en que la materia se convierte en espíritu, un proceso que

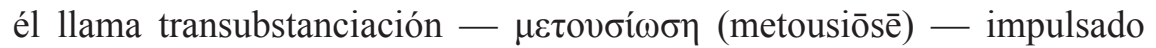
por el pensamiento bergsoniano y cristiano. Por último, el objetivo de Kazantzakis era salvarse de la salvación. El verso de Durrell en la obra Sappho "Libertad, Libertad, la cárcel de los libres" (Durrell, Sappho 69) corresponde al de Kazantzakis: "Tenemos que salvarnos de la salvación" (Carta al Greco 491).

Kazantzakis consideró deber del hombre: "resistir toda tentación de interrumpir el viaje prematuramente en las estaciones que parecen ser el final, pero no son realmente el final (el verdadero fin es la Nada) [y que] debemos amar todas las cosas sin apegarnos a ninguna" (Bien 544). Uno se adhiere fácilmente a las ideas y en ese sentido nosotros podemos recordar de Durrell cuatro "M": el monoteísmo, el mesianismo, la monogamia y el materialismo, pero es aún más fácil seguir a la mujer y esto fue un leitmotiv en la escritura de Kazantzakis. Durrell y Kazantzakis compartieron la época en que vivían: aunque Kazantzakis era mayor, tenían muchas influencias, lecturas e intereses comunes y ambos concebían el arte como un medio de dar sentido y estructura al caos de la existencia: esta fue una de las preocupaciones fundamentales del Modernismo, un movimiento al cual Kazantzakis, de hecho, pertenece (ver Beaton). Y ellos también compartieron sus raíces en el clasicismo y el misticismo. En este punto surgen dos preguntas: ¿se conocieron?, ¿se leyeron el uno al otro? Si Kazantzakis lo hizo, no confesaría haberlo hecho. Él rara vez menciona a sus contemporáneos o los reconoció como influencias. Tenía una buena dosis de megalomanía y sólo quería equipararse a los grandes nombres del pasado. Creo que debido a que Durrell era conocido, es probable que Kazantzakis hubiera leído algunos de sus libros, especialmente los relativos a Grecia.

Por el contrario, hay algunas referencias en los textos de Durrell acerca de Kazantzakis. Por ejemplo, Durrell menciona La Odisea: "El gran viaje de Ulises en el poema de Kazantzakis adquiere un sabor heroico y semi-mítico, como si se tratara de una antigua crónica o una especie de poema colectivo" (Greek Islands, 41). También se refiere a Kazantzakis como "la mente cretense más representativa de hoy, expresando anhelos extraños de la revelación mística, y una creencia extraña en un futuro 
heroico del hombre" y se refiere a Zorba como "una maravillosa evocación de un paisaje, $\mathrm{y}$ un boceto de un temperamento tan válidamente griego como el del propio Odiseo" (Greek Islands, 83). Aunque Kazantzakis quería que todos los seres humanos fueran iguales, las mujeres siguieron siendo un misterio para él. Las amaba y respetaba, pero a veces no entendía a las mujeres de su vida. Sin embargo, hizo retratos psicológicos de ellas en sus escritos. No obstante, junto a esos retratos se pueden encontrar los clichés típicos de la época, a saber, que las mujeres son incapaces de tener aspiraciones espirituales e intelectuales, su naturaleza las vincula a la tierra y la maternidad y es por eso que encarnan un peligro para el hombre, cuyo propósito es la dominación. Todos estos prejuicios estaban teñidos por los años y las relaciones con las mujeres (y hombres) que escaparon de tal simplicidad.

En la obra de Kazantzakis, las mujeres aparecen ya sea como un "ayudante" o como el antagonista del personaje masculino, el héroe. Ella recibe el deseo sexual del hombre, un deseo que se convierte en un problema para la mayoría de los héroes en los textos de Kazantzakis: "No hay heroína dominante o protagonista femenina en ninguna de sus obras, porque la pasividad, la inactividad, la debilidad, la gentileza, la feminidad, corroería el espíritu tenaz y la fibra de héroes como Zorba, Capitán Mijalis, Capitán Polyxinguis, Padre Yanaros, Papa Fotis, Odiseo, y hasta su santo Francisco de Asís" (Poulakidas 177). En la literatura de viaje de Kazantzakis, por ejemplo, nos encontramos con las españolas maternales, la peligrosa belleza femenina del paisaje del Peloponeso y el misterio de la mujer japonesa, pero rara vez es el retrato de una mujer en particular. Sin embargo, creo que hay mujeres fuertes en la obra de Kazantzakis, mujeres que a menudo amenazan a sus homólogos masculinos incompletos, pero que también pueden ser el medio para lograr la síntesis y la integridad de la pareja.

La Odisea fue escrita por Kazantzakis entre 1924 y 1938 y fue publicada por primera vez en inglés en 1957 con traducción de Kimon Friar. El personaje principal de este largo poema de treinta y tres mil trescientos treinta y tres versos es Ulises. El segundo personaje es una mujer, Helena de Troya. Ella huye lejos de Esparta con el héroe, pero esta vez lo hace de buena gana y no es secuestrada como lo fue por París cuando era más joven (Odisea 4, 1142-45). Las razones que la llevan a dejar a Menelao son fáciles de entender: se ha convertido en viejo y débil y ella se siente alentada por su debilidad, toma el papel activo, y se convierte en el "macho". En 
Creta se convierte en cómplice de Ulises para destruir el reino decadente de Idomeneo y después decide quedarse allí. Ella queda embarazada de un bárbaro rubio cuya sangre se mezclará con su espíritu clásico y dará a luz a una nueva raza. Para Odiseo ella encarna el amor espiritual: "Nunca había anhelado el abrazo de Helena, la-seductora-de-hombres / Lejos de juegos amorosos, lo atraía la lasciva mujer / en las más altas atalayas del espíritu, en la cima del deseo...más allá de la dulzura impúdica del eros, / más allá de las vergüenzas de la carne y la viscosidad del beso." (Odisea, trad. Castillo Didier, 3, 670-75). Sin embargo, ella sigue siendo la mujer más hermosa y además muy sensual. Existe, de hecho, una imagen de amor lésbico entre Helena y Krino, la princesa más joven de Creta y una doncella. Friar describe esto de la siguiente manera: "Krino ha sido extrañamente atraída por la belleza de Helena; las dos mujeres se besan y se acarician bajo el ardiente sol hasta que Idomeneo, enfurecido por los celos, ordena a Krino jugar con el toro más feroz de todos, que en secreto ha sido alimentado con hierbas irritantes e intoxicantes. Aunque ella sabe que va a su muerte, Krino juega acrobáticamente con el toro, es corneada de repente, arrojada en el aire y luego cae empalada en el estandarte de doble hacha del DiosToro"(785). Esta andrógina -y desafortunada- doncella llamada Krino (es decir, Lirio) que juega con el toro es en realidad una princesa cnossia y sólo puede ser la "princesa de los lirios" en el famoso fresco del palacio. Este uso de la zona arqueológica como algo más que un escenario es un ejemplo de un patrón que se encuentra en la épica de Kazantzakis.

Helena es representada como una mujer inteligente, fuerte e independiente que se siente atraída por otras mujeres. Durrell describe varias parejas homosexuales en sus novelas y todas ellas son relaciones fallidas, tal como esta. Clea es una de esas mujeres con inclinaciones lésbicas, mientras que Justine y Livia son ambas figuras andróginas como Krino (ver Nichols 71, 83). Clea es también una mujer distante de belleza abrumadora, amiga y confesora de hombres como Darley, tal como Helena lo es para Odiseo. Y al igual que Justine, la amistad con ella "parecía mucho más peligrosa que un amor fundado en la atracción sexual" (Durrell, The Alexandria 28). Junto a Krino encontramos a su hermana Fida (Serpiente), quien fue compañera de Krino en una obra temprana de Kazantzakis, Lirio y Serpiente. Fida es "la hija mayor del rey, que odia el reino decadente de su padre y planea un levantamiento con los esclavos y su grupo de mujeres dedicadas, las Rebeldes" (Friar 784). Ella es, sin duda, una mujer fuerte, una luchadora. Un personaje femenino similar se encuentra en 
La Odisea: Rala la revolucionaria en Egipto, una judía joven parecida a Rahel Lipstein, una amiga (y amante) de Kazantzakis a quien conoció en Viena en la década de 1920 y cuyo comunismo le atrajo a Kazantzakis. Si el cambio va a suceder, Kazantzakis parece decirnos, será la mujer la que lo implante. Esto también aparece en la obra de Durrell: "los amantes masculinos deben, la mayoría de las veces, ser seducidos a la acción por las Justines y Livias a su alrededor" (Nichols 54). Por lo tanto, postulo que las mujeres de ficción de Kazantzakis no son tan secundarias como puede parecer a primera vista y que en personajes como Helena, Krino, Fida o Rala tenemos un homenaje a las mujeres reales que amaba y admiraba. En oposición a Krino y Fida hay una tercera hermana, la princesa Dijtena. Cuando Odiseo y su tripulación llegan al palacio por primera vez "está siendo adornado con lirios y palmas por las Hermanas de la Serpiente, sacerdotisas de la Madre Tierra. En medio de los leopardos y sus tres amantes Negros, Dijtena aparece por un momento, la segunda hija del rey, la sacerdotisa de las sagradas rameras" (Friar 784).

Dijtena actúa como una nueva Ariadna en el poema: su nombre proviene del monte Dicte en Creta y significa "red". Una red está hecha de hilo, como el de Ariadna y es una trampa usada para pescar y perseguirnos. Los animales son perseguidos y los hombres también. Al igual que el mítico personaje, ella conducirá al héroe hacia el misterio de la isla, al centro de un ritual de fertilidad, y ella le ayudará a matar a la bestia interior (en este caso, su propio padre, Idomeneo). Ella va a dejar su tierra natal con él y, como Ariadna, pronto será abandonada mientras duerme (ver González-Vaquerizo < http://www.ucm.es/info/amaltea/ revista/num1/gvaquerizo.pdf $>$ ). En contraste con su mítica antecesora, Dijtena asume un papel activo en seducir al extranjero y no se arrepiente de la situación. Dejada a su suerte en un puerto egipcio, ella se despierta y al ver abundancia de fuertes marineros a su alrededor, sonríe. Ella es abandonada por su amante, pero no le importa. Después que su amante le hizo el amor, él la deja "Porque el sexo fuerte y la relación de amor son la perfecta libertad" (Nichols 57). Además, hay varios paralelismos para Dijtena entre las mujeres de Durrell. Ella es la ramera y, por lo tanto, se asemeja a Melissa, aunque esta última tiene un paralelo más probable con María Magdalena, mientras que la primera es una seductora, un misterio, y en ese sentido se acerca más a Justine: "Al igual que Ariadna, Justine le enseña a Darley cómo navegar por la laberíntica Alejandría. A cambio, ella es abandonada por él" (Nichols 74). Como un agente controlador en 
su relación con Odiseo, Dijtena es paralela tanto a Justine como a Livia "que utilizan a sus hombres y los dejan. Ellas parecen no tener ningún compromiso con nada más que su propio placer" (Nichols 77). Al igual que Livia, ella es irresistible para los hombres, pero es "un callejón sin salida emocional y psíquico-sexual. Deben dejarla y seguir su camino" (Nichols 84). Hay, por lo tanto, varios tipos de mujeres en La Odisea: doméstica (Penélope), sensual (Calipso), libre (Helena), entregadas a una causa (Rala, Fida), prostituta sagrada (Dijtena) y virgen sagrada (Krino) (ver Holliday). Las mujeres en las novelas de Kazantzakis responden a personajes similares a los que se observan en su épica.

Kazantzakis escribió que "Zorba me enseñó a amar la vida y no temer a la muerte" (Carta al Greco 6). Zorba encarna el mundo pagano saludable: la vida, la alegría, la carnalidad y él es la vida sin culpa, la naturaleza en estado puro. El protagonista -el "jefe", un escritor mitad griego mitad inglés- es un espectador temeroso de la vida y las mujeres. Mientras Zorba tendrá un romance con Madame Hortanse que da sentido a los últimos días de su vida, el escritor, después de muchas vacilaciones, duerme con una hermosa viuda de la ciudad. El sexo con Hortanse es un acto de generosidad de Zorba, que el jefe es incapaz de lograr con la viuda. Ellos gritan, ríen y fingen amarse, y ella muere junto a él. El escritor de la novela de Durrell es como el filósofo abstracto que "no puede entender la solidaridad de la carne. Es una lección que las mujeres de Durrell, finalmente, no permiten que sus hombres se olviden" (Nichols 42). Esto nos recuerda el sabio consejo que un viejo musulmán da a Zorba: "Si una mujer duerme sola, pone en vergüenza a todos los hombres. Dios tiene un corazón muy grande, pero hay un pecado que Él no perdonará. Cuando una mujer llama a un hombre a su cama y él no va" (110).

Libertad o Muerte es probablemente la novela más interesante para las cuestiones de género que Kazantzakis ha escrito. En su artículo titulado "Género y modernidad en la obra de Hesse y Kazantzakis" Evi Petropoulou argumenta que en las novelas de Kazantzakis, como norma, las mujeres sucumben a la voluntad del hombre. Pero la articulación de la identidad femenina concreta como en el personaje de Eminé en Libertad o Muerte no se ajusta a esta norma: "Eminé domina al sucumbir al deseo del hombre, pero sin despojarse de su feminidad. Ella es la femenina absoluta por "ser" un hombre (como Justine). Ella posee cualidades masculinas y pensamiento inmoral -es decir, inmorales en el contexto de las costumbres vigentes- que se manifiestan en sus deseos y prácticas sexuales...porque 
ella asume una posición de sujeto... ella desea al hombre, ella lo elige y a partir de ahora, él se convertirá en el objeto. Una vez que el hombre cae en la construcción del amor ideada por ella, le resulta indeseable" (<http://dx.doi.org/10.7771/1481-4374.1065>). El argumento se vuelve incompleto. Su marido Nouri-Bey, por ejemplo, resulta seriamente herido en sus genitales en su duelo con Manousakas. La misma pérdida de la masculinidad se ve en algunos de los personajes masculinos de Durrell: Blandford está metafóricamente castrado por Constanza (The Avignon 169-70) y Julian, en La Revuelta, también se convierte en un individuo impotente. En la novela de Kazantzakis Eminé elige ser bautizada con el nombre cristiano Helena. Lejos de ser coincidencia, su nombre habla de la clase de mujer que defiende su propia identidad mediante la autoafirmación sexual.

En La Última Tentación de Cristo de Kazantzakis leemos que: "No somos hombres, que tienen necesidad de otra vida, de una eterna; sino mujeres, y para nosotras un momento con el hombre que amamos es eterno Paraíso, un momento lejos del hombre que amamos es el Infierno eterno. Es aquí en la tierra que nosotras las mujeres amamos nuestra eternidad" (353). La mujer que habla es María Magdalena, una prostituta. Al igual que Melissa, ella tiene la compasión y disposición a sacrificar lo que necesitan los hombres incompletos que las rodean y como María Magdalena también asume la soledad. Una prostituta posee el don de la "caridad", se entrega profundamente, mientras que los hombres de su vida sólo pueden tomar de ella y esto la convierte en un ser superior a él, ya que "Ella tiene algo que dar... Ella es la productiva" (Nichols 64-65). No exige nada de los hombres inseguros a su alrededor. En el caso de María Magdalena el hombre incompleto, a pesar que esto pueda sonar hereje, es Jesús. El "hombre incompleto" parece ser un personaje recurrente en ambos escritores. Las mujeres de la ficción de Durrell son más fuertes que los hombres y los escritores y alter egos del autor están dispuestos a aprender y amar a las mujeres, independientemente de si esto no los hace autónomos de ellas. En contraste, los personajes femeninos de Kazantzakis, cuando son más fuertes que los hombres, los debilitan, los feminizan y ellas, a su vez, se masculinizan. Los hombres no se dan cuenta de lo mucho que pueden aprender de las mujeres y así luchan contra ellas. Pero esto resulta ser un error puesto que, ambos, las mujeres y los hombres pierden en esta batalla. El hombre típico es "un hombre profundamente inseguro, atado al pasado, ignorante del valor de otros seres humanos, verdaderamente incapaz de 
actuar independientemente, e igualmente incapaz de hacer valer un sistema de valores humanos, personal, independiente de la parcialidad y prejuicios de su cultura"(Nichols 101). Esto puede decirse de Julián, pero también describe un típico héroe kazantzakiano como el capitán Mijalis.

Siguiendo con mi planteamiento anterior, es claro que el papel de las mujeres individuales en la ficción de Kazantzakis no es de subordinación como se ha argumentado generalmente (véase, por ejemplo, Alexiou; Armeni, Iatropoulou-Theocharidou, Nikitopoulou; Poulakidas; RosenthalKamarinea; Stamatios). Si Kazantzakis es un misógino cuando se trata de las mujeres, también es un misántropo cuando se trata de la humanidad en su conjunto. Las mujeres individuales de Kazantzakis son descritas como amantes, esposas o madres, de acuerdo con su relación o función con los hombres, ellas pueden ser consideradas como domésticas, sensuales, libres, entregadas a una causa, prostitutas sagradas o vírgenes sagradas. La mayoría de estas funciones también se pueden encontrar en las novelas de Durrell, pero aquí presto atención a la mujer nutricia, a la mujer como una diosa y la prostituta sagrada, ya que la relación especial que las mujeres mantienen con la naturaleza en ambos autores, es notable.

En La Odisea Dijtena representa la Gran Madre de la religión cretense, la Madre Tierra. Ella es una personificación del Cazador, la

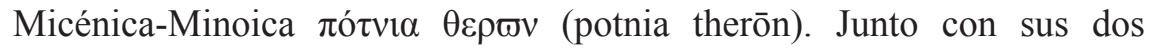
hermanas, Fida y Krino, encarna los diversos atributos de la deidad pagana. Ella tiene muchos amantes, como Justine "Pero", como Clea diría "el llamarla ninfómana... le quita toda su sustancia mítica. Como todas las personas amorales, bordea la calidad de Diosa" (Durrell, La Alexandria 77). También Benedicta en La Revuelta de Afrodita es una madre nutricia y las madres son las mujeres más perdurables en la imaginación y la ficción de Durrell (Nichols 121-25). Para la mujer, la fecundidad es, sin duda, su misterio y su poder. En cuanto a Kazantzakis, hemos visto el caso de Helena en La Odisea. Si el cuerpo de la mujer es sagrado como lo es en el pensamiento pagano, "cualquier negación del cuerpo y sus necesidades es una profunda falsa virtud" (Nichols 112). De hecho, los principios cristianos son contrarios a la vida. Así, las mujeres de Durrell viven más allá de ellos. En la obra de Kazantzakis cada mujer que intenta escapar de su naturaleza (y por tanto de la vida) falla, como la viuda en Zorba, mientras que las mujeres que aceptan la carnalidad de sus espíritus tienen éxito como Helena, Dijtena e incluso María Magdalena. En cuanto a Eminé, que se comporta como un hombre, es una mujer fracasada, como Justine. Las mujeres de 
Durrell son libres y liberan, a su vez, a los hombres. Lo que es más, liberan a los hombres del "horrible mundo, pseudo-ascético y privador de la vida impuesto por la falsa virtud cristiana y bondad espiritual" (Nichols 47) y las mujeres de Kazantzakis se convierten en seres independientes cuando asumen una de sus funciones en lo que respecta a los hombres: prostitutas, esposas, santas, etc.

Todas las mujeres de Durrell son caras de la misma Diosa ancestral. Melissa, por ejemplo, "se asemeja a una de esas antiguas diosas en que sus atributos proliferaron a través de su vida" (The Alexandria 136). Todas ellas representan un misterio y el misterio es el de su fecundidad. Kazantzakis reconoció su rol fértil a las mujeres y creía en el poder de la imaginación para crear el mundo, pero Durrell fue más allá al narrar que las mujeres son la esencia creativa. Las biografías siempre son necesarias para comprender al ser humano y esto es aún más cierto cuando se trata de escritores como Kazantzakis y Durrell. Nunca nos imaginaríamos su relación con las mujeres en la vida real sólo por la lectura de sus novelas. Así, la biografía en este caso es un medio para explicar la obra de arte. Como afirma Richard Pine "la escritura de Durrell se alineó de manera curiosa con su vida afectiva" (55). De hecho, ninguna de las biografías de los autores coinciden con su trabajo y hay una especie de quiasmo entre la vida y la obra en las novelas de los dos escritores: Kazantzakis trataba a sus mujeres amablemente en la vida y mal en sus escritos y Durrell, que pudo haber abusado y haber tenido una relación incestuosa con su hermana, las ensalzó en su obra (Nichols 9). Las mujeres de ficción de Durrell son grandes criaturas y el sexo más fuerte. Pero las mujeres en la vida cotidiana a menudo eran maltratadas por él. Se dice que "Durrell bebió mucho una buena parte de su vida, y es indiscutible que él podía ser intensamente cruel y brutal en el aspecto psicológico con los que le rodeaban" (Nichols 19). En contraste, Kazantzakis era extremadamente sensible a los demás y duro sólo consigo mismo. Él concibió, en primera instancia, a la mujer como débil y dócil, tal y como las mujeres de su familia podrían haber sido.

Mientras que Durrell no pensó en su esposa Nancy como un igual intelectual, Kazantzakis animó a sus dos esposas, Galatea y Heleni, a escribir. Él no consideraba a las mujeres como seres inferiores intelectualmente. Fue una chica joven, por ejemplo, la primera que lo introdujo en la filosofía de Nietzsche. En cuanto a Durrell, "Justine era un resumen andante de los escritores y los pensadores a quien ella había amado y admirado, pero ¿qué mujer inteligente es más que eso?” (The Alexandria 
164). Sin embargo, Kazantzakis enfrentó a las mujeres como un desafío a sus objetivos: "En los momentos espirituales más críticos había una mujer a mi lado" (Gandria, Berlin). Tal vez, porque mi crisis espiritual explotó en contacto con las mujeres. Y ella es la misma mujer eterna con sus efímeras máscaras individuales, con diferentes nombres, razas"(Prevelakis 13). Los dos tuvieron muchas amantes, ambos se casaron más de una vez y solían renovar las relaciones con las mujeres rápidamente. Después de la ruptura de su matrimonio con Nancy, Durrell empezó una nueva relación con Eve inmediatamente después de la ruptura. Y después de Eve, aunque Henry Miller sugirió que no debía encontrar otra compañera "con demasiada prisa” (Nichols 20), él se enamoró de Claude-Marie. Diez años más tarde se casó con Ghislaine, una chica más joven, y luego conoció y se casó con Françoise.

Kazantzakis también encontraba mujeres y empezaba relaciones con ellas en rápida sucesión: su mujer bohemia Galatea Alexiou, la joven y revolucionaria austríaca Rahel Lipstein junto con su grupo de amigos radicales, la filósofa griega Elli Lambridi ("Mudita"), una chica alemana y culta, Elsa Lange, las "sirenas" Barvara Nikolaevna Tamankiev y Frieda, y su compañera de toda la vida Heleni Samiou. Galatea tuvo fama como la musa del artista; era hermosa, inteligente e independiente. Llevaba pantalones, fumaba, tuvo varias relaciones con hombres y escribió novelas. Después de casarse en la iglesia de San Constantino se trasladaron a vivir a Atenas. La vida bohemia que Durrell tuvo con Nancy se corresponde con la vida de Kazantzakis y Galatea. El dinero era escaso para ambas parejas. Nichols nos informa que "la relación entre él y su mujer artística y bien educada (Nancy) se deterioró aún más (cuando vinieron a París y sus burdeles)... y Durrell no ayudó a que la situación mejorara" (16). La misma actitud se observa en Galatea y Nikos, puesto que él no trata de ocultar que está viendo a otras mujeres y cuando conoce a Heleni se hace evidente que Galatea pertenece al pasado. La relación con Heleni Kazantzakis es diferente, pues ella acepta y ama a las otras mujeres en su vida y no se casaron sino hasta 1945, diecinueve años después de haber comenzado su relación y lo hicieron sólo con el fin de obtener una visa para entrar a los EE.UU.

En su vida y obra ambos escritores parecen sentirse atraídos por mujeres más fuertes que son capaces de hacerse cargo de ellos. Los últimos días y meses de su vida, Durrell era completamente dependiente de su última esposa Françoise, una mujer "inteligente, joven, agresiva, sexual, 
y determinada"(Nichols 24). Él la amaba y estaba dominado por ella. Su relación se asemeja a la de Kazantzakis con su primera esposa Galatea. Le escribía cartas desde Viena reconociendo su incapacidad para hacerla feliz. Esas cartas, como Peter Hartocollis sugiere "dan la impresión de un hombre que depende en gran medida de su esposa. Él no sólo se describe a sí mismo como perdido sin ella, impotente y triste, pensando en ella y suplicándole que venga y se una a él, sino que constantemente le pide que haga cosas por él, que tramite sus asuntos con los editores y los banqueros, que consiga y le envíe dinero, ropa o artículos para el hogar. De hecho, la mayoría de las cartas se leen como una lista de deseos que un niño le da a su madre cuando ella va a ir de compras" (207-8). Sin embargo, una diferencia significativa entre Kazantzakis y Durrell es que Kazantzakis (como muchos de sus héroes) se sintió amenazado por las mujeres, mientras que para Durrell no fue así. Barbara Nikolaevna Tamankiev, por ejemplo, era el tipo de mujer sirena, una tentadora. Ella era hermosa y le ofreció Kazantzakis cuando él trabajaba para el gobierno griego en la repatriación de los griegos de la región del Cáucaso, dejar todo y huir con ella. El rechazó en un gesto que repetirían muchos de sus héroes. La Sirena "permanecería misteriosa y efímera, perdida para siempre, suya para siempre" (Kazantzakis, Heleni 95).

Otra tentación que Durrell no habría rechazado ocurrió en Viena. Después de un encuentro por la noche con una mujer joven en la oscuridad de una sala de cine, Kazantzakis se infectó de una extraña enfermedad que le provocó una hinchazón facial. El Dr. Wilhelm Stekel (discípulo de Jung) le dijo que sufría de lo que una vez fue llamado "enfermedad del asceta" (Hartocolis 207). Estas anécdotas muestran las contradicciones religiosas profundas vividas por Kazantzakis. Sin embargo, las mujeres no siempre fueron una amenaza para él. Hay en este sentido un testimonio revelador de Kazantzakis relativo a las mujeres en su vida y sobre todo la última, Heleni: es en el epílogo de Carta al Greco donde escribió que "Tuve la suerte de conocer a mujeres extraordinarias a lo largo de mi ruta. Ningún hombre me hizo tanto bien o ayudó a mi lucha en la medida en que lo hicieron estas mujeres -y una por encima de todas, la última... Tuvimos buenas esposas, la suya se llamaba Jerónima, la mía Heleni... Pero no permitimos que las mujeres, incluso las más queridas, nos llevaran por mal camino. No hemos seguido su camino cubierto de flores, las llevamos con nosotros. No, no las llevamos, estas intrépidas compañeras siguieron nuestros ascensos por su propia voluntad" (476). 
En conclusión, para Durrell como para Kazantzakis las relaciones hombre-mujer son complicadas, pero el género se necesita entre sí para completarse. El hombre da a la mujer seguridad sólo cuando ella, a su vez, lo ha hecho sentir pleno. Para poder convertirse en el medio para la libertad del hombre, su guía en la vida y su canal de la sabiduría, ella también tiene que ser liberada. Por lo tanto, Durrell exige una mujer más fuerte, un hombre menos dominante y, como tal, un nuevo tipo de pareja. Kazantzakis encuentra profundas diferencias entre hombres y mujeres. El hombre, de acuerdo con su naturaleza, busca los espacios abiertos de su mente espiritual. La mujer, por el contrario, obedece a una fuerza ctónica que la une a las raíces animales del ser humano. Sin embargo, estas fuerzas opuestas son igualmente esenciales para la vida y, por lo tanto, la pareja ideal en Durrell se corresponde con la síntesis ideal de los hombres y mujeres en Kazantzakis. Las relaciones de Durrell con las mujeres son problemáticas e incluso despóticas, sin embargo, en sus novelas las mujeres representan el medio para la plenitud de un hombre. Kazantzakis fue un querido amigo y amante de muchas mujeres inteligentes, pero en su obra a menudo las mujeres encarnan un obstáculo a las propuestas de sus homólogos masculinos. Durrell creía que una nueva relación biológica -es decir, el hombre cada vez más femenino y viceversa- podría dar lugar a un tipo diferente de sociedad. Kazantzakis se mantuvo un paso atrás al tanto de lo incompleto de los hombres y mujeres y sus necesidades en busca de la síntesis. En suma, un enfoque comparativo de Durrell y Kazantzakis, tanto en lo que respecta a sus biografías como a sus novelas puede cambiar nuestros estereotipos relativos a la identidad de género y el papel de la mujer en el trabajo y la vida de los autores, mostrando paralelismos inesperados entre sus personajes femeninos ${ }^{2}$.

2 Traducción por Alfredo Fredericksen Neira. Mail de contacto: alfredericksen@ gmail.com. Quisiera dedicar este humilde trabajo de traducción a mi padre, Alfredo Fredericksen Gallardo y a mi madre, Virginia Neira Zárate. Hoy, todo el tiempo en que permanecí ausente -más nunca distante de corazón-, da sus frutos

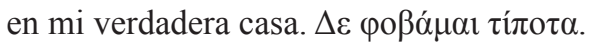




\section{Referencias Bibliográficas}

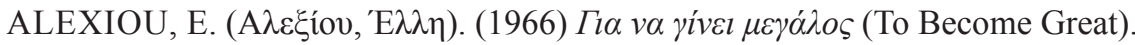
Athina: Dorikos.

ARMENI, A.; IATROPOULOU-THEOCHARIDOU, M. and

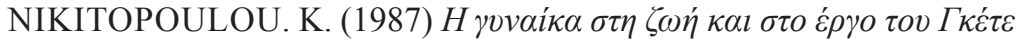

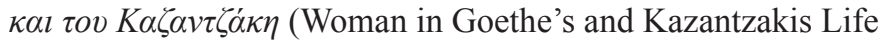
and Work). Athina: Phōtoplano.

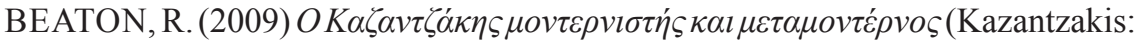
Modernist and Postmodernist). Athina: Kastaniotis-Panepistimio Kritis.

BIEN, P. (2007) Kazantzakis: Politics of the Spirit. Princeton: Princeton UP.

DURRELL, L. (1969) Sappho. London: Faber \& Faber.

DURRELL, L. (1968) The Alexandria Quartet. London: Faber and Faber.

DURRELL, L. (1992) The Avignon Quintet. London: Faber and Faber.

DURRELL, L. (1978) The Greek Islands. London: Faber and Faber.

DURRELL, L. (1974) The Revolt of Aphrodite. London: Faber and Faber.

FRIAR, K. (1958) "Translation, Introduction, Synopsis and Notes". The Odyssey: A Modern Sequel. By Nikos Kazantzakis.

New York: Simon and Schuster, 1958. i-xxxviii, 777-820.

GIFFORD, J. (1999) "Reading Orientalism and the Crisis of Epistemology in the Novels of Lawrence Durrell." CLCWeb: Comparative Literature and Culture 1.2 (1999): <http://dx.doi.org/10.7771/1481-4374.1036>.

GONZÁLEZ-VAQUERIZO, H. (2009). "El laberinto cretense en la Odisea de Nikos Kazantzakis" ("Cretan Labyrinth in Nikos Kazantzakis's Odyssey"). Amaltea: Revista de Mitocritica 1: $<$ http://www.ucm.es/info/amaltea/revista/num1/gvaquerizo.pdf $>$.

HARTOCOLLIS, P. (1973) "Mysticism and Violence: The Case of Nikos Kazantzakis." International Journal of Psycho-Analysis 55: 205-10.

HOLLIDAY, V. (1978) “The Feminine Melody in Kazantzakis's Odyssey”. Neo-Hellenika 3: 56-67.

KAZANTZAKIS, H. [Eleni] (1968). Nikos Kazantzakis: A Biography Based on His Letters. Trans. Amy Mims. New York: Simon and Schuster.

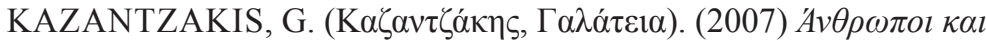
$v \pi \varepsilon \rho \alpha \dot{v} \theta \rho \omega \pi o l$ (Men and Overmen). Athina: Kastaniotis.

KAZANTZAKIS, N. (1954) Freedom or Death. Trans. Jonathan Griffin. New York: Simon and Schuster.

KAZANTZAKIS, N. (1965) Report to Greco. Trans. Peter Bien. New York: Simon and Schuster. 
KAZANTZAKIS, N. (1980). Serpent and Lily: A Novella, with a Manifesto: The Sickness of the Age. Trans. Theodora Vasils. Berkeley: U. of California.

KAZANTZAKIS, N. (1988) The Last Temptation of Christ. Trans. Peter Bien. New York: Simon and Schuster.

KAZANTZAKIS, N. (2013) Odisea. Traducción, estudios y síntesis de Miguel Castillo Didier. Santiago: Tajamar Editores.

KAZANTZAKIS, N. (1954) The Odyssey: A Modern Sequel. Trans. Kimon Friar. New York: Simon and Schuster.

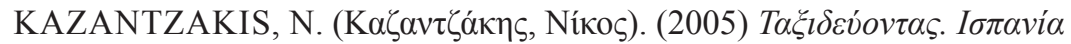
(Travelling: Spain). Athina: E. Kazantzakis.

KAZANTZAKIS, N. (1961) Zorba the Greek. Trans. Carl Wildman. London: Faber and Faber.

NICHOLS, J. (2011) The Stronger Sex. Madison-Teaneck: Farleigh Dickinson UP.

PETROPOULOU, E. (2000) "Gender and Modernity in the Work of Hesse and Kazantzakis." CLCWeb: Comparative Literature and Culture 2.1 (2000): $<\mathrm{http}: / / \mathrm{dx}$. doi.org/10.7771/1481-4374.1065>.

PINE, R. (1994) Lawrence Durrell: The Mindscape. New York: St. Martin's P.

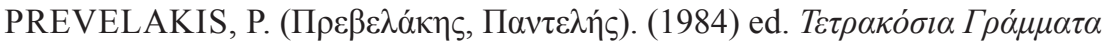

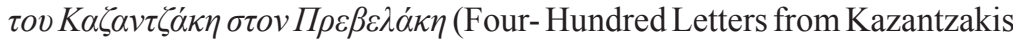
to Prevelakis). Athina: Kazantzakis.

POULAKIDAS, A. (1972) “Kazantzakis' Recurrent Victim: Woman.” Southern Humanities Review 6: 177-89.

ROSENTHAL-KAMARINEA, I. (1983) "Bemerkungen zur Typologie von Mann und Frau bei Nikos Kazantzakis." Hellenika: Jahrbuch für die Freunde Griechenlands: 29-40.

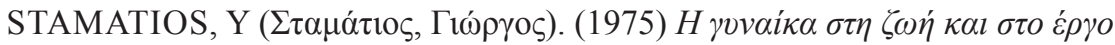

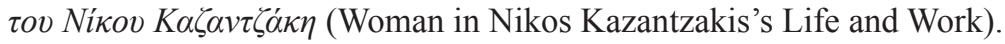
Athina: n.p. 